\title{
O Parto Humanizado no contexto atual: Uma revisão integrativa
}

\author{
Humanized childbirth in the current context: An integrative review \\ Parto humanizado en el contexto actual: Una revisión integradora
}

Luma de Oliveira Morais $^{1^{*}}$, Francine Ribeiro Potros ${ }^{1}$, Priscila Ribeiro Maia ${ }^{1}$, Karen Lorrane Maria Antunes Rabelo1, Fernanda Miranda Ribeiro1, Kamila Lima Abrantes de Matos², Ézio Junio Gonçalves Nunes ${ }^{3}$, Célia Carvalho Cavalcante ${ }^{4}$, Talitha Zileno Pereira ${ }^{4}$, Lenilson Prates da Silva ${ }^{5}$, Laila Thamires Gomes Santana1.

\section{RESUMO}

Objetivo: Realizar uma revisão integrativa da assistência ao parto humanizado, assunto de relevância médica. Métodos: Foi realizada revisão de literatura consultando artigos científicos indexados nas bases eletrônicas Literatura Latino-Americana e do Caribe em Ciências da Saúde (LILACS), Scientific Eletronic Library Online (SCIELO), Medical Literature Analysis and Retrieval System Online (MEDLINE) publicados no período de 2000 a 2018 nos idiomas português e inglês. Resultados: A fim de devolver à mulher seu papel de protagonista durante o parto e oferecer uma assistência de qualidade técnica e humanizada, a Organização Mundial da Saúde e o Ministério da Saúde propuseram condutas a serem recomendadas nesse contexto. Todavia, ainda é visto a prática de intervenções desnecessárias que não consideram as evidências científicas ou as características individuais, sociais e culturais da parturiente, levando a resultados perinatais desfavoráveis, além de repercussões biopsicossociais negativas para a mesma. Considerações finais: $O$ ciclo gravídico-puerperal deve ser considerado evento natural e fisiológico em que a equipe de saúde respeite os desejos da parturiente. É preciso implementação e fiscalização de práticas de ensino humanizado e melhorias na qualidade dos serviços da saúde pública.

Palavras-chave: Parto Humanizado, Humanização da Assistência, Parto, Trabalho de parto, Parto normal.

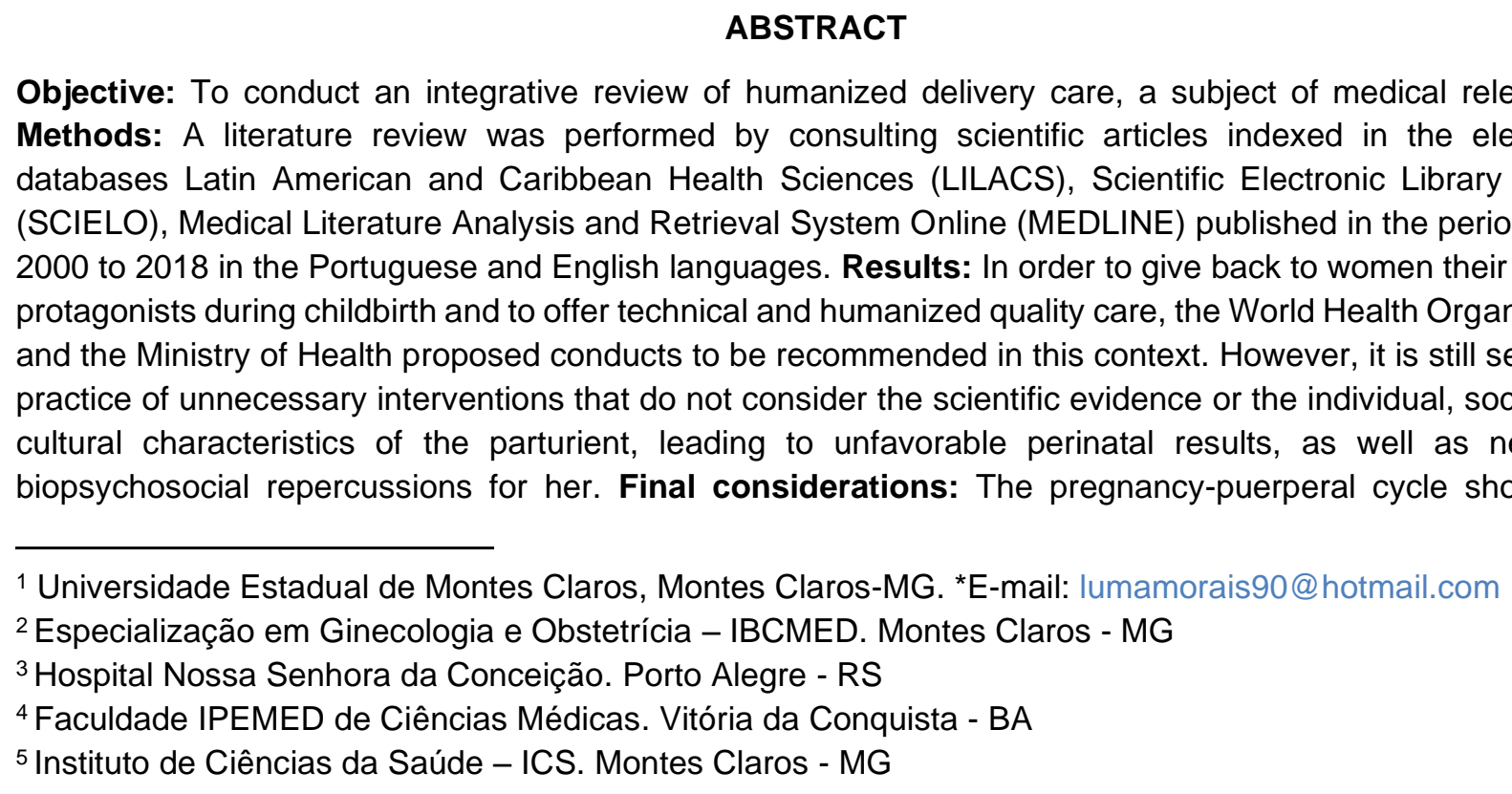

SUBMETIDO EM: 8/2019

ACEITO EM: 9/2019

PUBLICADO EM: 12/2019 
considered a natural and physiological event in which the health team respects the wishes of the parturient. It is necessary to implement and supervise humanized teaching practices and improve the quality of public health services.

Key words: Humanizing Delivery, Humanization of Assistance, Parturition, Parturition Labor, Natural Childbirth.

\section{RESUMEN}

Objetivo: realizar una revisión integradora de la atención humanizada del parto, una cuestión de relevancia médica. Métodos: se realizó una revisión de la literatura mediante la consulta de artículos científicos indexados en las bases de datos electrónicas de Ciencias de la Salud de América Latina y el Caribe (LILACS), la Biblioteca electrónica científica en línea (SCIELO), el Sistema de recuperación y análisis de literatura médica en línea (MEDLINE) publicado en el período del 2000 al 2018 en portugués e inglés. Resultados: para devolver a las mujeres su papel de protagonistas durante el parto y ofrecer atención técnica y humanizada de calidad, la Organización Mundial de la Salud y el Ministerio de Salud propusieron conductas recomendadas en este contexto. Sin embargo, todavía se observa la práctica de intervenciones innecesarias que no consideran la evidencia científica o las características individuales, sociales y culturales de la parturienta, lo que lleva a resultados perinatales desfavorables, así como a repercusiones biopsicosociales negativas para ella. Consideraciones finales: El ciclo embarazo-puerperal debe considerarse un evento natural y fisiológico en el que el equipo de salud respeta los deseos de la parturienta. Es necesario implementar y supervisar las prácticas de enseñanza humanizadas y mejorar la calidad de los servicios de salud pública.

Palabras clave: Parto Humanizado, Humanización de la Atención, Parto, Trabajo de Parto, Parto normal.

\section{INTRODUÇÃO}

Segundo a Organização Mundial de Saúde (OMS), 2000, a definição de humanização do parto é um aglomerado de condutas que evitam procedimentos desnecessários e de risco, e simultaneamente promovem o parto e nascimento saudáveis, respeitando o processo natural (MATEI EM, et al., 2003).

Há quatro princípios relevantes que se relaciona com a assistência humanizada: respeito, beneficência, não maleficência e justiça. Em relação ao respeito, a autonomia por suas próprias escolhas no caso da parturiente, bem como de evitar danos ao indivíduo com pouca autonomia, como o bebê, é fundamental. Já o princípio da beneficência é a que se deve como profissionais da saúde proporcionar o máximo de benefícios ao binômio mãe-filho. Além disso, no que tange ao princípio da não maleficência é relevante prezar pelo mínimo de dano aos indivíduos envolvidos (SOUZA TG, et al., 2011).

O parto e nascimento mudaram drasticamente no século XX, em épocas remotas ocorria em ambiente familiar e atualmente com o avanço médico e tecnológico esses eventos passaram a ocorrer em ambiente hospitalar. Desde 1980, intensificaram as taxas de intervenções médicas com o uso de anestésicos peridural e aumentou o número de procedimentos cirúrgico - cesárias. Inúmeras são as vantagens para essa mudança: é possível controlar complicações e há menos risco de vida para os envolvidos. Entretanto, é imprescindível que os profissionais da saúde fiquem atentos quanto a humanização do parto. Os principais ônus relacionados a institucionalização é que se impõe rotinas e padronizações que inviabilizam o cuidado de maneira individual e única, contribuindo para a desumanização do parto (BEHRUZI R, et al., 2011; SOUZA TG, et al., 2011; APOLINÁRIO D, et al., 2011; DODOU HD, et al., 2017).

Sobretudo, não é incomum nos dias de hoje a ocorrência de violência obstétrica que se traduz como a apropriação pelo profissional da saúde da autonomia da parturiente, associando a fisiologia do processo com procedimentos e medicamentos desnecessários, instituindo assim a patologização do parto (SOUZA AB e SILVA LC, 2016). 
Existem diversos tipos de violência durante o trabalho de parto: violência institucional, em que tem uma dificuldade de acesso das pessoas menos favorecidas e pouca infraestrutura; violência moral, relaciona-se as condutas profissionais inadequadas com supervalorização de tecnologias e carência de decisão da parturiente; violência física, que se associa a práticas desnecessárias como litotomia, manobra de Kristeller, toques violentos e excessivos, episiotomia, amniotomia e uso de ocitocina; é importante ressaltar que informar a paciente de maneira equivocada também configura violência física; violência sexual, pouco descrito na literatura e violência psicológica e verbal. Há um predisposição na obstetrícia para esse tipo de ato uma vez que existe uma relação direta com o gênero feminino, e sobretudo, mulheres que experimentaram o aborto, principalmente, o aborto provocado são por vezes negligenciadas no serviço de saúde (MARTINS ADC e BARROS GM, 2016).

A violência obstétrica é considerada pela OMS como uma violação dos direitos humanos. Ainda segundo esse órgão, a vivência do parto vaginal deve ser de maneira espontânea, com a gestante com liberdade para se movimentar e receber monitoração contínua (batimentos cardíacos fetais, alimentação, posição não supina, partograma) e, principalmente, presença de acompanhante. Esse tipo de violência tem repercussões desastrosas na vida da mulher, além da experiência negativa do parto, como por exemplo efeito psicológico negativos para a mulher, passando para as próximas gerações, distúrbios sexuais subsequentes e aumento da morbimortalidade materna (SOUZA AB e SILVA LC, 2016).

Inúmeras políticas públicas e programas surgiram nas últimas décadas para tentar minimizar os problemas envolvidos na assistência obstétrica, entre eles em 2000 surgiu o programa para Humanização do Pré-natal e do Nascimento (PHPN) para garantir uma assistência obstétrica mais eficiente e proporcionar a mulher mais autonomia e individualidade com intervenções racionalizadas. Entretanto, apesar disso, a humanização do parto ainda representa um desafio para os profissionais de saúde e instituições públicas. Não obstante, em 1984, o Ministério da Saúde já havia inaugurado o Programa de Atenção Integral à Saúde da Mulher e em 1990 o Programa de Cuidados Integrados para à Saúde da Mulher. Já em 2011 surgiu a "Stork Network" para completar o PHPN e é um programa mais centrado na experiência do parto (DODOU HD, et al., 2017; APOLINÁRIO D, et al., 2011).

Este artigo tem como objetivo fazer uma revisão de literatura analisando acerca da assistência ao parto e a humanização destes serviços, uma vez que é um assunto de extrema relevância na medicina e muito discutido na atualidade.

\section{MÉTODOS}

Neste estudo foi realizada uma pesquisa de revisão integrativa de literatura e como fonte de dados foi consultados artigos científicos nas bases eletrônicas Literatura Latino-Americana e do Caribe em Ciências da Saúde (LILACS), Scientific Eletronic Library Online (SCIELO), Medical Literature Analysis and Retrieval System Online (MEDLINE) publicados em periódicos no período de 2000 a 2018.

O Quadro 1 apresenta as principais informações das publicações selecionadas como autor, revista, objetivo, principais resultados.

Utilizamos com etapas para sua produção: elaboração do objetivo; selecionando os artigos mais relevantes para o tema; discussões dos resultados e finalmente a conclusão deste estudo.

Os critérios de inclusão definidos foram: estudos disponíveis em sua totalidade, gratuitos, publicados nos últimos anos, nos idiomas português e inglês. Foram excluídos da busca inicial capítulos de livros, artigos que não abordassem o tema proposto, resumos, textos incompletos e relatos técnicos. 
Quadro 1 - Distribuição dos estudos segundo autor, revista, objetivo e principais resultados.

\begin{tabular}{|c|c|c|c|}
\hline Autor & Revista & Objetivo & Principais resultados \\
\hline $\begin{array}{l}\text { Andrade PON, } \\
\text { et al. (2016) }\end{array}$ & $\begin{array}{lr}\text { Revista } & \text { Brasileira de } \\
\text { Saúde } & \text { Maternidade } \\
\text { Infantil } & \end{array}$ & $\begin{array}{l}\text { Analisar fatores associados à violência obstétrica } \\
\text { em uma maternidade de Recife na assistência ao } \\
\text { parto vaginal }\end{array}$ & $\begin{array}{l}\text { As práticas não recomendadas mais prevalentes foram esforço de puxo }(65 \%) \text {, uso } \\
\text { de ocitocina }(41 \%) \text { e posição supina/litotomia de forma rotineira (39\%). }\end{array}$ \\
\hline $\begin{array}{l}\text { Apolinário D, } \\
\text { et al. }(2016)\end{array}$ & Revista Rene & $\begin{array}{l}\text { Apontar práticas na assistência ao parto e } \\
\text { nascimento sob a perspectiva das puérperas em } \\
\text { uma maternidade }\end{array}$ & $\begin{array}{l}\text { Práticas a serem mais bem estimuladas: respeito à privacidade da mulher e seu } \\
\text { direito de acompanhante. Dentre as práticas a serem eliminadas está a posição de } \\
\text { litotomia. }\end{array}$ \\
\hline $\begin{array}{l}\text { Behruzi R, et } \\
\text { al. (2011) }\end{array}$ & BMC Women's Health & $\begin{array}{l}\text { Explorar os fatores organizacionais e culturais } \\
\text { associados aos cuidados obstétricos } \\
\text { humanizados em um hospital em Quebec, } \\
\text { Canadá }\end{array}$ & $\begin{array}{l}\text { O modelo de assistência centrado na família constituiu um fator facilitador às } \\
\text { práticas humanizadas, no entanto, as principais barreiras encontradas foram falta } \\
\text { de comunicação entre os profissionais, e, consequentemente, falta de privacidade } \\
\text { e continuidade dos cuidados. }\end{array}$ \\
\hline $\begin{array}{l}\text { Dodou HD, et } \\
\text { al. }(2017)\end{array}$ & $\begin{array}{l}\text { Rev. pesqui. } \\
\text { fundam. (Online) }\end{array}$ & $\begin{array}{l}\text { Evidenciar a atenção recebida durante a } \\
\text { internação em uma maternidade pública na } \\
\text { perspectiva das puérperas }\end{array}$ & $\begin{array}{l}\text { As puérperas relataram como dificuldades aventadas: a falta de acompanhamento } \\
\text { durante o trabalho de parto, ausência de informações e comportamento insensível } \\
\text { por parte de alguns profissionais. }\end{array}$ \\
\hline $\begin{array}{l}\text { Mabuchi AS, et } \\
\text { AL (2008) }\end{array}$ & $\begin{array}{l}\text { Acta Paulista de } \\
\text { Enfermagem }\end{array}$ & $\begin{array}{l}\text { Entender o significado que o profissional de } \\
\text { saúde que atende a parturiente dá ao trabalho de } \\
\text { parto e ao parto humanizado. }\end{array}$ & $\begin{array}{l}\text { Há discordância entre o que se entende por parto humanizado e o que se realiza } \\
\text { na prática. }\end{array}$ \\
\hline $\begin{array}{l}\text { Martins ADC, } \\
\text { et al. }(2016)\end{array}$ & Revista Dor & $\begin{array}{l}\text { Discutir sobre violência obstétrica no sistema } \\
\text { público de saúde no Brasil }\end{array}$ & $\begin{array}{l}\text { Foram identificadas como tipos de violência obstétrica: a violência sexual, } \\
\text { psicológica, verbal, física e moral. }\end{array}$ \\
\hline $\begin{array}{l}\text { Matei EM, et al } \\
(2003)\end{array}$ & $\begin{array}{l}\text { Centro Universitário } \mathrm{S} . \\
\text { Camilo }\end{array}$ & $\begin{array}{l}\text { Conhecer o perfil de puérperas com relação a } \\
\text { idade, pré-natal, tipo de parto a que foram } \\
\text { submetidas e verificar se os seus direitos } \\
\text { preconizados pela OMS estão sendo respeitados } \\
\text { na prática obstétrica. }\end{array}$ & $\begin{array}{l}\text { Muitos direitos das parturientes preconizados pela OMS não estão sendo } \\
\text { respeitados na população estudada. }\end{array}$ \\
\hline $\begin{array}{l}\text { Nagahama } \\
\text { EEl, et al. } \\
(2008)\end{array}$ & $\begin{array}{l}\text { Cadernos de saúde } \\
\text { pública }\end{array}$ & $\begin{array}{l}\text { Definir a prática do cuidado humanizado nos } \\
\text { hospitais bem como estabelecer os obstáculos } \\
\text { enfrentados para sua implantação }\end{array}$ & $\begin{array}{l}\text { A estrutura física deficiente e falta de organização da própria instituição são } \\
\text { grandes problemas frente a humanização do parto. }\end{array}$ \\
\hline $\begin{array}{l}\text { Oliveira VJ, et } \\
\text { al. (2017) }\end{array}$ & $\begin{array}{ll}\text { Texto } & \text { Contexto } \\
\text { Enfermagem } & \end{array}$ & $\begin{array}{l}\text { Analisar os discursos das mulheres e dos } \\
\text { profissionais de saúde sobre assistência ao parto }\end{array}$ & $\begin{array}{l}\text { Há a presença da violência obstétrica e a enfermagem encontra dificuldades em } \\
\text { garantir os direitos das parturientes na cena do parto; as parturientes mantem certo } \\
\text { consentimento; outros profissionais negam a ocorrência. }\end{array}$ \\
\hline $\begin{array}{l}\text { Souza } A B \text {, et } \\
\text { al. }(2016)\end{array}$ & Revista Ciências Médicas & $\begin{array}{l}\text { Analisar questões relacionadas a violência } \\
\text { obstétrica institucional }\end{array}$ & $\begin{array}{l}\text { Caracteriza os médicos e a equipe de enfermagem como os principais promotores } \\
\text { de violência obstétrica. }\end{array}$ \\
\hline $\begin{array}{l}\text { Souza TG, et } \\
\text { al. }(2011)\end{array}$ & $\begin{array}{l}\text { Revista Gaúcha } \\
\text { Enfermagem }\end{array}$ & $\begin{array}{l}\text { Identificar como o parto humanizado é percebido } \\
\text { pelos profissionais de saúde atuantes dessa área }\end{array}$ & Existe uma falta de preparo dos profissionais para a prática do parto humanizado. \\
\hline $\begin{array}{l}\text { Vargens OMC, } \\
\text { et al (2017) }\end{array}$ & Escola Anna Nery & $\begin{array}{l}\text { Constatar práticas obstétricas empregadas por } \\
\text { enfermeiras na assistência ao parto em } \\
\text { maternidades públicas e suas colaborações na } \\
\text { consolidação da humanização do parto e } \\
\text { nascimento. }\end{array}$ & $\begin{array}{l}\text { As práticas mais recorrentes foram aquelas que não afetam a fisiologia. Práticas } \\
\text { intervencionistas mostram um processo ainda em transformação. }\end{array}$ \\
\hline
\end{tabular}

Fonte: Morais LO, et al., 2019.

REAS/EJCH | Vol.Sup.37 | e1375 | DOI: https://doi.org/10.25248/reas.e1375.2019 Página $\mathbf{4}$ de $\mathbf{7}$ 


\section{RESULTADOS E DISCUSSÃO}

A institucionalização do parto e os avanços tecnológicos e científicos da medicina contribuíram para as mudanças que o ciclo gravídico-puerperal sofreu com o passar dos anos, em que o uso dessas novas tecnologias passou a ser sinônimo de cuidado qualificado. Nos anos 80 , condutas invasivas, caracterizadas por autoritarismo e falta de evidências científicas predominavam no campo obstétrico. Há duas décadas, a OMS reuniu informações baseadas em evidências e então propôs quais condutas eram de fato recomendadas e deveriam ser mantidas; aquelas que requerem cautela para sua aplicação; e quais devem ser abandonadas pelo potencial risco prejudicial (VARGENS OMC, et al., 2017; ANDRADE PON, et al., 2016; MARTINS ADC e BARROS GM, 2016).

A partir desse documento da OMS, o Ministério da Saúde vem ao longo dos últimos anos pondo em voga diversas estratégias com o objetivo de oferecer um serviço de pré-natal de melhor qualidade, ampliando seu acesso e cobertura, além de garantir que a assistência ao parto às gestantes e ao recém-nascido, bem como a assistência ao puerpério, estejam de acordo com os direitos de cidadania. Baseado nessa perspectiva, no ano de 2000, o Programa de Humanização no Pré-Natal e Nascimento (PHPN) foi criado a fim de garantir que as instituições e os profissionais de saúde seguissem o que foi preconizado para devolver à mulher seu papel de protagonista durante o parto e oferecer uma assistência de qualidade técnica e humanizada ao mesmo tempo (SOUZA TG, et al., 2011; ANDRADE PON, et al., 2016).

Após duas décadas de orientações à prática do modelo de humanização da assistência ao parto, a realidade de muitos hospitais não condiz com o que é preconizado pelo Ministério da Saúde e OMS. Apesar dos profissionais envolvidos conhecerem os principais aspectos da humanização, observa-se que a adesão aos seus princípios tem se mostrado insuficiente para reverter o modelo intervencionista da atenção obstétrica. Uma vez que a frequência das intervenções é significativamente maior em mulheres com gestações consideradas de risco habitual, é possível afirmar que essas intervenções são frequentemente realizadas de forma rotineira, sendo, portanto, desnecessárias, além de não levarem em conta as características individuais, sociais e culturais da parturiente ou as evidências científicas (MINISTÉRIO DA SAÚDE, 2002; SOUZA TG, et al., 2011; ANDRADE PON, et al., 2016).

Nosso país apresenta uma das maiores taxas de cesarianas e intervenções obstétricas, principalmente por procedimentos como amniotomia, infusão endovenosa de ocitocina sintética, analgesia intraparto, episiotomia e manobra de Kristeller. Soma-se a esse cenário, o alto índice de morbimortalidade materna do Brasil e o dado de que uma entre quatro mulheres sofre violência durante o parto, principalmente em forma de condutas desrespeitosas e violência verbal (VARGENS OMC, et al., 2017; ANDRADE PON, et al., 2016).

Essas práticas não ocorrem de forma homogênea em todos os segmentos populacionais. As taxas de cesarianas são ainda mais altas na rede privada, podendo chegar a cerca de $85 \%$ dos partos. Em contrapartida, a violência obstétrica se dá preferencialmente em hospitais públicos e em segmentos populacionais menos favorecidos do ponto de vista socioeconômico e naquelas mulheres com menor nível de escolaridade, condições nas quais é mais difícil as mulheres fazerem valer os seus direitos ou questionarem tais condutas. Por outro lado, um maior grau de instrução relaciona-se a menor número de intervenções, além de ser acompanhada por uma enfermeira obstétrica durante o parto associa-se a maior frequência de boas práticas (ANDRADE PON, et al., 2016; MARTINS ADC e BARROS GM, 2016).

Uma vez que o momento do parto passou a ser considerado como evento hospitalar, seu seguimento é controlado por meios tecnológicos e cirúrgicos em que a maternidade possui o poder de decisão sob o binômio mãe-filho e conduz o processo de maneira independente, sendo que caberia à mãe o direito de autonomia sobre as escolhas que lhe dizem respeito. Nesse contexto, o parto deixa de ser um evento fisiológico e a mulher passa a ser tratada como um ser passivo com necessidade de múltiplas intervenções para que o nascimento do filho possa ocorrer. Constitui, portanto, um modelo tecnocrático, institucionalizado e intervencionista, colocando a mulher na condição de paciente, sem autonomia sobre seu corpo, separando-a de seus familiares e de seu filho de forma precoce, uma vez que muitos desses procedimentos e intervenções 
deveriam ocorrer apenas quando corretamente indicados (SOUZA TG, et al., 2011; MARTINS ADC e BARROS GM, 2016; VARGENS OMC, et al., 2017).

A realização do parto no ambiente hospitalar, associado a disponibilidade tecnológica no cuidado a saúde, contribuiu para organização da assistência como uma linha de produção, acentuando a medicalização do parto, cuja capacidade de escolha passa a ser de responsabilidade exclusiva do médico, a despeito do desejo das mulheres, que perdem sua privacidade e autonomia (OLIVEIRA VJ e PENNA CMM, 2017).

A OMS preconiza que o parto deve ter início de forma natural, não induzida. A todo momento, a mulher tem o direito de se movimentar livremente, adotando a posição que lhe for mais confortável e a recusa a intervenções de costume, recebendo todo o suporte necessário como monitoramento cardíaco, uso do partograma e alimentação. Além disso, a parturiente deve ter a sua privacidade respeitada e o direito a presença de acompanhantes garantido (ANDRADE PON, et al., 2016).

Percebendo a presença do acompanhante como benéfica no processo de trabalho de parto/nascimento, esta foi vista como um diferencial no modelo de parto humanizado, capaz de proporcionar à parturiente inúmeros benefícios durante todo o processo, permitindo que a mulher visualizasse a parturição de forma mais segura, protegida e, consequentemente, experienciasse uma diminuição na sensação dolorosa. Dessa forma, o direito a ter um acompanhante durante o trabalho de parto é garantido por lei, através da portaria número 569 de $1^{\circ}$ de junho de 2000 do Ministério da Saúde, desde que a instituição de saúde tenha condições físicas de recebê-lo regulamentou que as instituições de saúde devem possibilitar à gestante o direito a ter um acompanhante no período de pré-parto e parto, desde que a estrutura física do estabelecimento ofereça condições necessárias. Essa regulamentação foi de extrema importância, mas ainda enfrenta desafios para implementação de forma plena, uma vez que envolve diversas questões, como a capacitação dos profissionais de saúde para acolher esses acompanhantes, a própria aceitação da equipe em relação a presença do acompanhante, bem como a estruturação física adequada do ambiente hospitalar (MINISTÉRIO DA SAÚDE, 2000; SOUZA TG, et al., 2011; MABUCHI AS e FUSTINONI SM, 2008)

No processo de humanização, a estrutura física do hospital tem papel importante. Muitos problemas enfrentados são a falta de condições para receber o acompanhante da parturiente no espaço da sala de parto, falta de materiais (como a bola) e manutenção de equipamentos, há dificuldade em manter a privacidade da gestante em salas de parto comuns e com menos espaço, grande demanda do serviço e estrutura física reduzida. Isso repercute negativamente na realização de atividades consideradas essenciais no processo de trabalho em equipe, comprometendo de modo significativo a qualidade dos serviços prestados, contribuindo para a desumanização do trabalho e da atenção à saúde, bem como para a insatisfação dos usuários. Constata-se também que o enfrentamento cotidiano das carências dos serviços influencia claramente na condição física e emocional dos trabalhadores e desestimula a adesão a um modelo pautado na integralidade, na promoção da saúde e no enfoque interdisciplinar de atuação (DODOU HD, et al., 2017).

Associado à necessidade de reestruturação física das instituições de saúde, a capacitação profissional com relação a humanização do parto, tanto na graduação quanto nos cursos de formação continuada dos hospitais, bem como a conscientização dos profissionais acerca da importância dessas práticas e a adoção de uma política de humanização nas instituições ainda são dificuldades enfrentadas para tornar o cuidado mais humanizado (DODOU HD, et al., 2017).

Além do despreparo profissional, a dificuldade de trabalhar em equipe interfere no atendimento integral a mulher e seu bebê, uma vez que para isso é necessário o trabalho interdisciplinar. Isso determina uma das grandes dificuldades da atualidade, que é a superação da fragmentação do trabalho, que é evidenciado pela especialização do saber e atuação das corporações profissionais. As dificuldades observadas no entrosamento, no trabalho em equipe e na divisão de tarefas entre profissional do nível superior e médio refletem uma divisão de poder na equipe, sendo a tomada de decisão centrada nos profissionais de nível superior (DODOU HD, et al., 2017).

A maternidade e o momento do nascimento do filho constituem uma das experiências mais importantes na vida das mulheres, podendo causar intensa ansiedade em relação ao parto e ao processo doloroso 
envolvido. Sendo assim, o parto não é visto apenas como um episódio fisiológico, mas sim um evento subjetivo e emocional que requer uma assistência adequada que respeite a integridade física e psíquica da mulher. Nesse contexto, destaca-se a necessidade da atenção humanizada para potencializar laços afetivos tanto entre a mãe e o filho quanto entre demais familiares, chamando atenção para a importância do acompanhante nesse processo. O intervencionismo excessivo acompanhado ou não de violência obstétrica pode ser danoso e prejudicial, levando a resultados perinatais desfavoráveis, além de repercussões biopsicossociais negativas para a parturiente, como lacerações perineais graves, infecções, hemorragias, incontinência urinária e fecal, prolongamento do trabalho de parto e do período expulsivo, disfunções sexuais e traumas psicológicos (NAGAHAMA EEI e SANTIAGO SM, 2008; ANDRADE PON, et al., 2016).

\section{CONSIDERAÇÕES FINAIS}

O ciclo gravídico-puerperal não deve ser considerado uma doença, com condutas autoritárias, sem evidências científicas e invasivas. É preciso resgatar o parto como um evento natural e fisiológico, em que a equipe de saúde conheça os limites e as necessidades da parturiente, respeitando suas escolhas, individualidades e singularidades. Apesar do conhecimento dos profissionais de saúde sobre as políticas e recomendações da OMS e do Ministério da Saúde, a prática nos hospitais não condiz com o que é preconizado. Dessa forma, é preciso a implementação e fiscalização, por parte dos gestores e das instituições, de práticas de ensino humanizado e melhorias na qualidade dos serviços da saúde pública, compreendendo o verdadeiro significado da humanização do parto e suas implicações positivas na vida da mulher.

\section{REFERÊNCIAS}

1. ANDRADE PON, et al. Fatores associados à violência obstétrica na assistência ao parto vaginal em uma maternidade de alta complexidade em Recife, Pernambuco. Rev. Bras. Saúde Materno-Infantil, 2016; 16(1): 29-37.

2. APOLINÁRIO D, et al. Práticas na atenção ao parto e nascimento sob perspectiva das puérperas. Rev. Rene, 2016; 17(1): 20-8.

3. BEHRUZI R, et al. The facilitating and barriers encountered in the adoption in a highly specialized university affliated hospital. BMC Women's Health, 2011; 11(1): 53.

4. DODOU HD, et al. O cuidado à mulher no contexto da maternidade: caminhos e desafios para a humanização. Rev. pesqui. cuid. fundam. (Online), 2017; 9(1): 222-230.

5. MABUCHI AS, FUSTINONI SM. O significado dado pelo profissional de saúde para trabalho de parto e parto humanizado. Acta Paul Enferm, 2008; 21(3):420-426.

6. MARTINS ADC, BARROS GM. Will you give birth in pain? Integrative review of violence in Brazilian public units. Rev. Dor, 2016; 17(3): 215-218.

7. MATEI EM, et al. Parto humanizado: um direito a ser respeitado. Centro Universitário S. Camilo, 2003; 9(2): 16-26.

8. MINISTÉRIO DA SAÚDE (BR). Secretaria de Assistência à Saúde. Portaria no 569/GM, de 1 de junho de 2000: institui o Programa de Humanização no Pré-Natal e Nascimento, no âmbito do Sistema Único de Saúde. Ministério da Saúde, 2000; Seção 1:4-6.

9. MINISTÉRIO DA SAÚDE (BR). Secretaria de Políticas de Saúde. Área Técnica de Saúde da Mulher. Parto, aborto e puerpério: assistência humanizada à mulher. Ministério da Saúde, 2001; (17): 145-157.

10. NAGAHAMA EEI, SANTIAGO SM. Práticas de atenção ao parto e os desafios para humanização do cuidado em dois hospitais vinculados ao Sistema Único de Saúde em município da Região Sul do Brasil. Cad. Saúde Pública, 2008; 24(8):1859-1868.

11. OLIVEIRA VJ, PENNA CMM. O discurso da violência obstétrica na voz das mulheres e dos profissionais de saúde. Texto Contexto Enferm, 2017; 26(2):e06500015.

12. SOUZA AB, SIILVA LC. Fatores associado a ocorrência de violência obstétrica institucional: uma revisão integrativa da literatura. Rev. Ciênc. Médicas, 2016; 25(3): 115-128.

13. SOUZA TG, et al. A humanização do nascimento: percepção dos profissionais de saúde que atuam na atenção ao parto. Rev. Gaúcha Enfermagem, 2011; 32(3): 479-486.

14. VARGENS OMC, et al. Contribuição de enfermeiras obstétricas para consolidação do parto humanizado em maternidades no Rio de Janeiro-Brasil. Esc. Anna Nery, 2017; 21(1): e20170015. 